This is the accepted manuscript of the article, which has been published in Acs Biomaterials Science \& Engineering. 2017, 3(7), 1273-1282. http://dx.doi.org/10.1021/acsbiomaterials.6b00746

\title{
Systemically administered, target-organ specific therapeutic recombinant proteins and nanoparticles for regenerative medicine
}

\author{
Tero AH Järvinen ${ }^{1,2^{*}}$, Jahidur Rashid ${ }^{3}$, Toini Valmari ${ }^{1}$, Ulrike May ${ }^{1}$, Stuart Prince ${ }^{1}$, Fakhrul Ahsan ${ }^{3}$ \\ ${ }^{1}$ School of Medicine, University of Tampere, Tampere, Finland \\ ${ }^{2}$ Department of Orthopedics \& Traumatology, Tampere University Hospital, Tampere, Finland \\ ${ }^{3}$ Department of Pharmaceutical Sciences, School of Pharmacy, Texas Tech University Health Sciences \\ Center, Amarillo, Texas, USA \\ *Address for correspondence: \\ Prof. Tero Järvinen, M.D., Ph.D. \\ School of Medicine, Fl-33014 University of Tampere, Finland \\ Phone: + 358-44-285 4620 \\ Email: blteja@uta.fi
}




\section{Abstract}

Growth factors and other therapeutic protein that could potentially enhance tissue regeneration have been identified, but their therapeutic value in clinical medicine has been almost non-existent for reasons such as difficulty to maintain bioactivity of locally applied proteins in the protease-rich environment of regenerating tissues. Although human diseases are treated with systemically administered drugs in general, all current efforts aimed at enhancing tissue repair with biological drugs have been based on their local application. The systemic administration of growth factors has been ruled out due to concerns about their safety. These concerns are warranted, because only a small proportion of systemically administered drugs reach their intended target. Selective delivery of the drug to the target tissue and use of functional protein domains capable of penetrating cells and tissues could alleviate these problems. We propose a novel approach utilizing unique molecular "Zip/postal codes" in the angiogenic vasculature forming at the regenerating tissues as a target for systemically administered, targeted therapies. The angiogenic vasculature allows target organ-specific delivery of systemically administered therapeutic molecules by affinity-based physical targeting (using peptides or antibodies as an "address tag") to injured tissues undergoing repair. Molecules with therapeutic potential can also be packaged into lipid or polymer-based nanocarriers (such as micelles, liposomes, and nanoerythrosomes) which then can be targeted to the desired location by inserting multiple copies of the targeting peptide on the surface of the nanoparticle. The desired outcome of the targeted therapies is increased local accumulation and lower systemic concentration of the therapeutic payload. We believe that the physical targeting of systemically administered therapeutic recombinant proteins could be rapidly adapted in the field of regenerative medicine. 
Key Words: Angiogenesis, tissue regeneration, in vivo phage display, decorin, vascular ZIP codes, regenerative medicine, recombinant proteins, cell penetrating peptides, nanocarrier, pulmonary arterial hypertension (PAH) 


\section{Local versus systemic drug delivery in regenerative medicine}

After an injury adult tissue react differently. Only some tissues, such as the bone, repair injuries with tissue that is identical to the original tissue. Most tissues, however, undergo a repair process where most of the injured tissue is replaced by non-functioning, fibrotic scar tissue, whereas the original tissue is only partly restored ${ }^{1,2}$.

Plenty of growth factors and other proteins have been identified that could potentially be used as drugs to enhance tissue regeneration, but their therapeutic application in regenerative medicine has been rather limited ${ }^{1,3,4}$. Only two of them have been approved by FDA to be used in humans; bone morphogenetic protein-2 (BMP-2) for treating fractures and platelet derived growth factor (PDGF) for treating chronic skin wounds that do not close ${ }^{4,5}$. However, neither of these recombinant growth factors is in wide use due to rather limited clinical therapeutic value. Furthermore, PDGF received a boxed warning from the U.S. Food and Drug Administration and has been withdrawn in Europe due to safety issues ${ }^{5}$. There are several, biological reasons for their failure in randomized clinical trials (RCTs): It is difficult to maintain bioactivity of locally administered therapeutic proteins because of a lack of retention of the agent within the regenerating tissue, poor tissue penetration, and instability of protein therapeutics in the protease-rich environment of the injured tissue, and side effects ${ }^{4,6}$. For example, when PDGF was used as a topical administration in skin wounds, supra-physiological doses were needed and treatment with the growth factor correlated with a five-times increased risk of cancer ${ }^{5}$. The problems encountered with PDGF illustrate well the importance of controlling not just the instability of the growth factors, but also their retention at the wound site and overcoming these 
challenges are probably the key for successful growth factor-based therapies ${ }^{5}$. Besides, most injuries are inaccessible for topically applied therapeutic molecules, especially if the injury hits multiple sites (tissues), which further limit the usefulness of local treatment.

Remarkably, all current efforts, even the most sophisticated ones, aiming to enhance tissue repair with biologic drugs have been based on local application of therapeutic molecules at the injured site ${ }^{4}$, 6,7. Although human diseases are treated with systemically administered drugs/recombinant proteins in general, systemic application of growth factors has been ruled out due to concerns about efficiency and potential safety. These concerns are warranted because the major problems in systemic drug therapy are that only a small proportion of administered drug reaches its intended target site(s) and as explained above for PDGF side effects such as increased cancer risk ${ }^{5}$. Moreover, large molecules such as antibodies have a poor tissue penetration and therefore do not reach the intended actual target cells ${ }^{8-11}$. Selective drug delivery to the target tissue and use of functional proteins, such as cell penetrating peptides proficient of penetrating cells and tissues, could alleviate some of the above mentioned problems ${ }^{11-14}$.

\section{Vascular Heterogeneity - Organ-specific postal code-system in vasculature}

Our growing knowledge of the molecular structure of blood vessels has revealed a practical application for organ/tissue-specific therapeutic treatment of various human diseases with systemically administered drugs ${ }^{8,12,13}$. Recent studies have shown that each organ has unique molecular structures in its blood vessels, so-called "vascular ZIP codes", essentially providing a built-in 
postal code system in our body (Figure 1) ${ }^{12,13,15-17}$. Each organ confers endothelial cells (ECs) in it with their "organotypic", i.e. unique tissue-specific features ${ }^{18,19}$. A unique combination of clusters of transcription factors, angiocrine growth factors, adhesion molecules and chemokines is expressed by the ECs of each organ, and so the blood vessels in each organ can be distinctly defined ${ }^{19}$. Moreover, during various diseases, disease-specific signatures are expressed on the vasculature of the diseased tissue ${ }^{17}$. This is particular apparent for diseases such as cancer, or tissue injuries, which both induce the growth of new blood vessels into the tissue by angiogenesis ${ }^{17}$. These angiogenic blood vessels are structurally distinct from the pre-existing blood vessels in rest of the body ${ }^{17}$ and thus, provide an appealing target for target organ-specific delivery of systemically administered drugs.

Hence, the disease and organ-specific molecular "Zip codes" in blood vessels can be exploited for target organ-specific delivery (to the diseased tissue) of systemically administered therapeutic molecules by affinity ligands ${ }^{12,}{ }^{15-17}$. This so-called affinity-based physical targeting (synaphic, pathotrophic, or active targeting) makes use of these vascular ZIP codes, i.e. molecular markers that are specifically expressed at the target, but not elsewhere in the body on healthy counterparts, ${ }^{12,17}$. The desired outcome of the synaphic targeting is increased local accumulation and lower systemic concentration of the therapeutic payload ${ }^{12}$. 


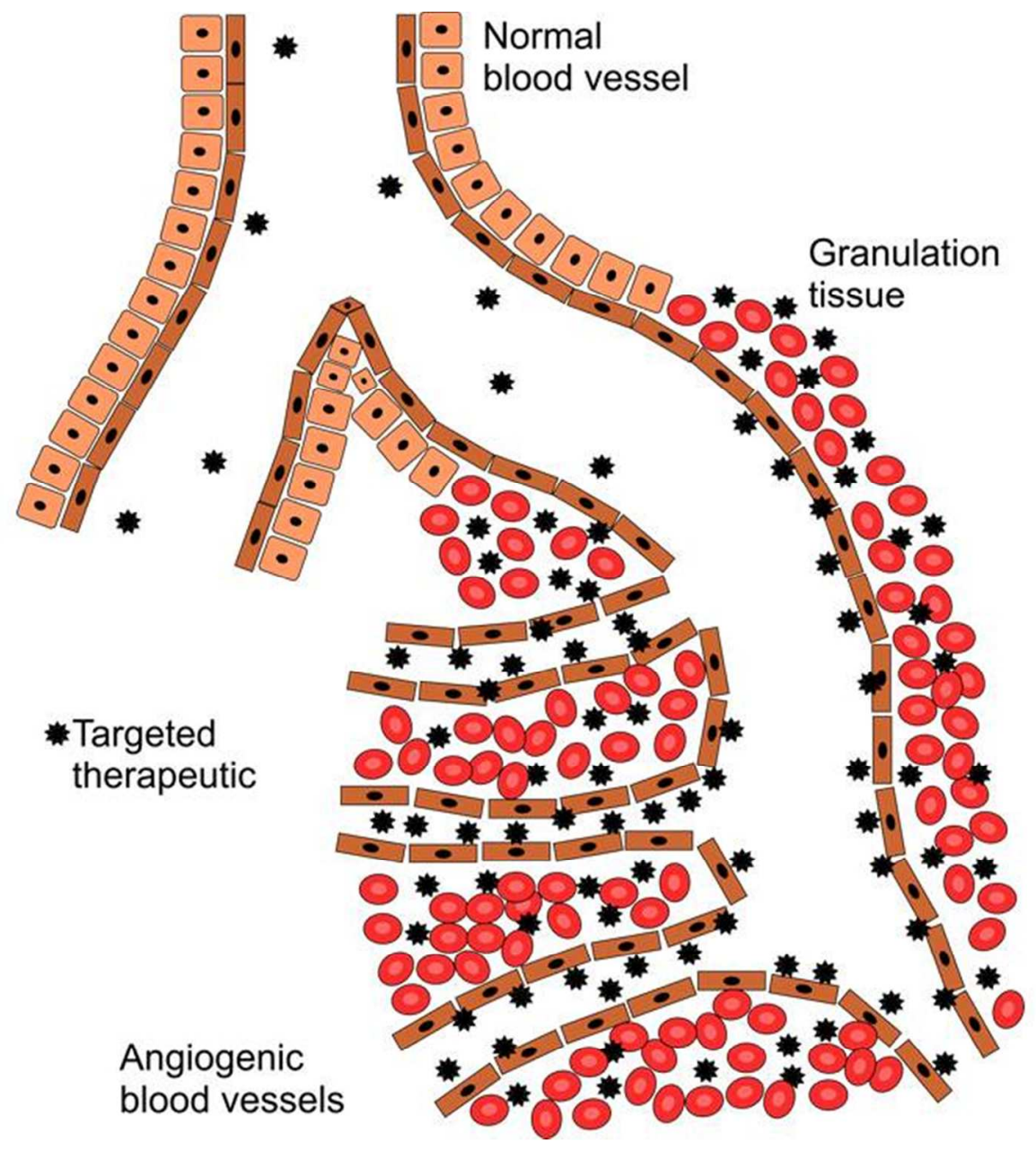

Figure 1. Target-specific drug therapies in tissue regeneration. Molecular "Zip/postal codes" in the angiogenic vasculature of the regenerating tissues allow target organ-specific delivery of the systemically administered therapeutic recombinant proteins by affinity-based physical targeting (using peptides or antibodies as an "address tag") to injured tissues undergoing repair. The desired outcome of the targeted therapies is similar to topical application: increased local accumulation of the recombinant protein in the target tissue and lower systemic concentration of the therapeutic payload. 


\section{Angiogenesis - a potential for vascular targeting in regenerative medicine}

Angiogenesis, the formation of new blood vessels, is an essential step for tissue regeneration because it allows a variety of mediators, nutrients, and oxygen to reach the healing tissue ${ }^{1-3,20,21}$. During regeneration of injured tissue, angiogenic capillary sprouts invade the fibrin/fibronectin-rich clot and within a few days form up into a thick microvascular network throughout the granulation tissue ${ }^{1-3,20,}$

22. These newly formed blood vessels that abundantly fill up and from the granulation tissue at the site of the injury, differ in their molecular "Zip/postal codes"” from pre-existing vasculature. Therefore they provide a fascinating possibility for vascular targeting of systemically administered drugs to improve tissue regeneration ${ }^{22,23}$.

\section{In vivo phage display}

Tissue specific vascular "ZIP codes" can be easily probed by in vivo phage display, a method first reported in $1996^{24}$. In vivo phage display allows unbiased investigation of vascular diversity by random peptide or cDNA libraries expressed as a part of the coat protein on the cell surface of bacteriophages (Figure 2) ${ }^{13,25}$. Due to the random protein fragments being the only difference between different phage particles in the library, phage display is a powerful method for screening an unlimited number of potential functional protein domains, because it provides a physical linkage between peptides (i.e. the phenotype), which are displayed on the surface of a bacteriophage particle, and the encoding DNA (genotype) ${ }^{13,25}$. 


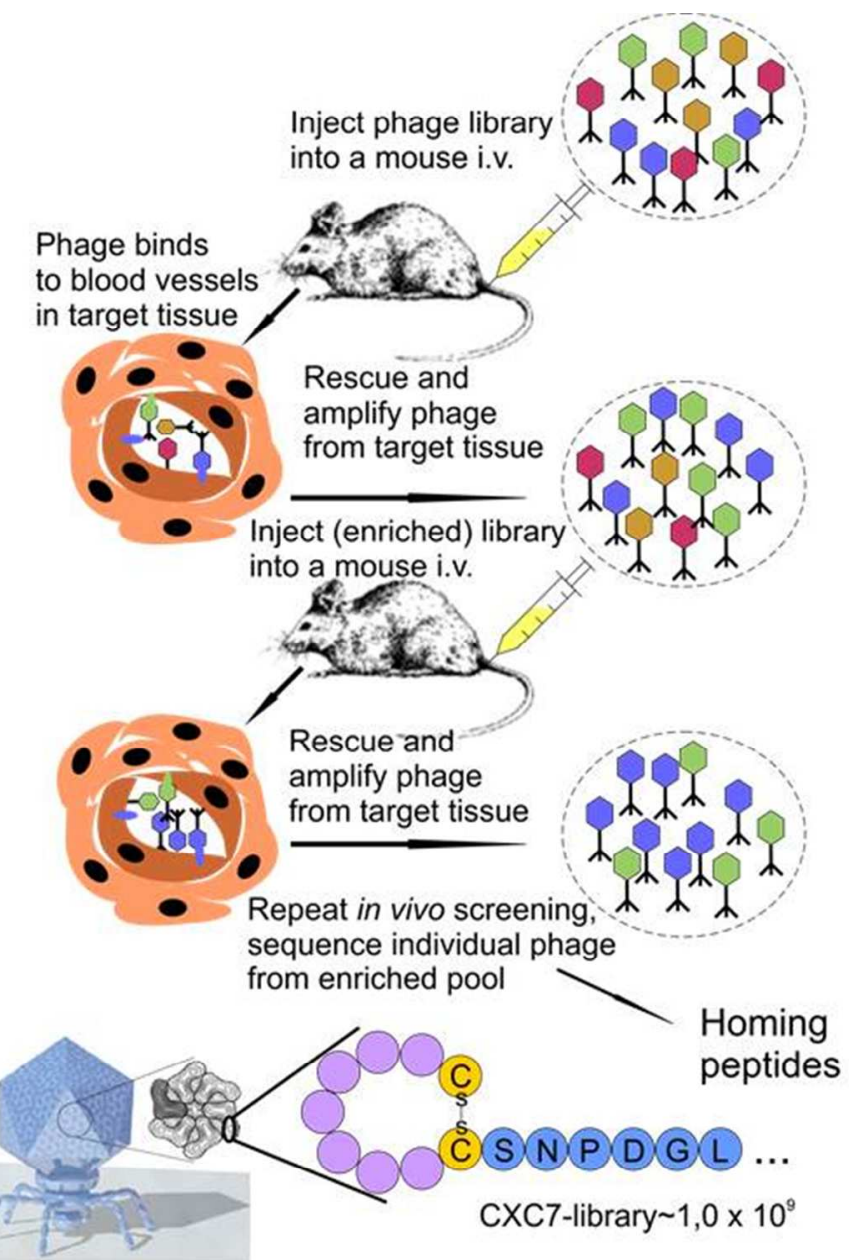

Figure 2. Schematic presentation of the principle of in vivo phage display. (a) A cyclic CX7Cpeptide library has been cloned to the C-terminus of the phage coat protein and expressed in 415 copies in T7 Select 415-1b phage. (b) A phage library is injected into circulation. The homing peptides on the phage surface bind to endothelium in the tissues, resulting in an enrichment of phages bound to the endothelium of the target tissue. Target tissue is homogenized, cell suspensions prepared, and the bound phage rescued and amplified by adding $E$. coli. The amplified phage pool recovered from the target tissue is then re-injected into mice at a similar disease stage, and the screening cycle is repeated several times to ensure that phage clones that specifically bind (i.e. home) towards target will be recovered. A set of phage clones is 
randomly collected from a homing phage population that shows enriched homing towards target tissue. The peptide-encoding DNA inserts are amplified by PCR, and the PCR products sequenced.

Bacteriophages can be genetically modified to incorporate random protein sequences fused to the coat proteins at a diversity of billions of variants per library, close to the total number of possible permutations $\left(20^{\mathrm{X}}\right.$, where $\mathrm{X}$ denotes number of amino acids) of a random amino acid sequence ${ }^{13}$. Generating a random phage library results in a pool of billions of bacteriophages all identical to each other except for the protein motif expressed at the end of its coat protein. For the in vivo selection, a library of phage displaying random peptides is injected systemically into the animals, followed by removal of target organ/tissue and amplification of the bound phage pool from the target organ, which is then subjected to another round of selection in new animals ${ }^{13}$. In vivo peptide phage screening combines subtractive elements (removal of phage displaying pan-specific peptides by all other organs of the body except the given target organ) with positive selection at the target tissue ${ }^{13}$. In vivo phage display offers a unique prospect to screen for an almost unlimited (potentially billions) number of potential protein-based drug candidates simultaneously in an in vivo setting ${ }^{13,25}$. Combination of in vivo phage display and bacterial 2-hybridization, in turn, allows simultaneous identification of ligand-receptor (ligand - peptide; receptor - receptors on the endothelial cells) pairs for the target organ-specific targeting ${ }^{26}$.

In the field of regenerative medicine in vivo phage display has been applied for several purposes: to identify peptides capable of binding to the blood clots formed after the injury ${ }^{27}$, homing to the 
angiogenic blood vessels forming at the injured tissues ${ }^{28}$, for the identification and illumination of neural structures during surgery ${ }^{29,30}$ and to identify peptides capable of homing to brain injury after the traumatic breakage of blood-brain barrier ${ }^{31}$.

\section{Systemically administered vascular homing peptides for regenerative medicine}

We concluded that it may be achievable to deliver systemically administered drugs into regenerating tissues via a target organ-specific approach independent of the location of the injury in the body ${ }^{28}$. For that purpose, in vivo phage display was used on injured tissues during angiogenesis to identify protein motifs capable of homing to the injured sites after systemic administration of phage libraries 28. Two peptides that selectively target injured tissues have been identified: CARSKNKDC (CAR) and CRKDKC (CRK) ${ }^{28}$. The CAR sequence is homologous to heparin-binding sites in various proteins and shows the highest homology with the main heparin-binding site of known angiogenic growth factor, BMP4 ${ }^{28}$. Indeed, the CAR peptide binds to cell surface heparan sulfate proteoglycans (HSPGs) and utilizes the HSPGs for efficient cell and tissue penetration ${ }^{28}$. The CRK peptide which is not capable of cell and tissue penetration ${ }^{28,32}$ shows structural similarity to segments in thrombospondin type 1 and 3 repeats identified in numerous proteins and has a potential cryptic cell penetration sequence, CendR-sequence in it ${ }^{28}$. These two vascular homing peptides have different targeting profiles: CAR peptide prefers early stages of tissue regeneration, whereas the CRK peptide preferably targets injured tissues at later stages of healing ${ }^{28}$. 


\section{Conjugated delivery - Multi-functional recombinant proteins}

By conjugating a conventional therapeutic effector molecule to a targeting element, a tissue-specific targeted, multi-functional therapeutic molecule is created. The conjugation of these two functional elements can be either carried out by chemical linkage or by expressing them together as a recombinant fusion protein. An example of such recombinant fusion protein is interleukin-10 (IL-10) fused to the antibody F8 (F8-IL10, i.e. Dekavil) that recognizes a domain of the extracellular matrix protein fibronectin, that is expressed exclusively in inflammatory vasculature ${ }^{33-36}$. This therapeutic fusion protein is in ongoing clinical trials to treat arthritis and to suppress rejection towards allografts in transplantation surgery ${ }^{34,36}$. Additional examples include Angiopep, a peptide used to target nanoparticles loaded with therapeutic molecules to brains in e.g. Parkinson's disease ${ }^{14}$, the tumor homing NRG-peptide fused together with tumor necrosis factor $\alpha$ (TNF $\alpha$ ) to induce anti-tumor reactions towards tumor cells ${ }^{37,}{ }^{38}$, interleukin-11 (IL-11) mimic peptide motif fused together with apoptosis inducing peptide sequence to halt tumor growth ${ }^{39}$ and RGR peptide expressed together with LIGHT protein to stabilize leaky, non-functional blood vessels ${ }^{40}$.

The half-life of the most common peptides used as targeting elements, is usually short in blood circulation and their binding affinity for their respective receptor relatively low ${ }^{22}$. However, both of these shortcomings can be substantially minimized by fusing the peptides to become a part of a larger recombinant protein or by coating cells or nanoparticles with multiple copies of the peptide ${ }^{12,22,41}$. For example, our preliminary data provide evidence that incorporation of CAR peptide into therapeutic proteins enhances their binding efficacy towards HSPGs to a nanomolar-level, and even more if the recombinant fusion protein is multimerized (expressed as a dimer) (unpublished). One-to- 
one peptide-payload (i.e. targeting element-therapeutic effector) conjugates can be quite effective despite the large size difference, particularly when the peptide is used to augment an inherent affinity of the payload to the target. Such examples are TNF $\alpha$ targeted to tumors by fusion to a tumor-homing peptide that is now in phase 3 clinical trials ${ }^{37,38}$, and CAR-peptide targeted decorin (DCN) ${ }^{42}$. DCN homes to angiogenic vasculature through a core protein-dependent interaction ${ }^{43}$, but despite its inherent homing ability, the CAR peptide was able to enhance the accumulation of the recombinant fusion protein into the sites of angiogenesis (wound) approximately $500 \%$ over the accumulation of native $\mathrm{DCN}^{42}$. Furthermore, a prime example of using multiple copies of a short targeting peptide ("painting") is the targeting of stem cells to desired loci ${ }^{41,44}$. Both CAR and CRK peptides have been used successfully, e.g. to target mesenchymal stem cells (MSCs) to infarcted myocardium after "painting" the surface of MSCs with multiple copies of the peptide ${ }^{41,44}$. 
A normal tissue target tissue

Figure 3. Systemically administered, targeted therapies. (a) Conjugated delivery. The drugs are physically conjugated to the targeting element in conventional drug targeting. For protein-based therapeutics, targeting domain and therapeutic molecule are fused together as a recombinant protein with enhanced activity and tissue-specificity. (b) - (c) Bystander effect. Therapeutic drug(s) co-injected with tissue-penetrating targeting peptides are transported across the vessel wall and through tissue together with the peptides. No actual physical connection is needed between them; the cell penetrating homing peptide "sweeps" co-injected drug(s) to its target (homing) tissue in a tissue-specific fashion. 
Even more striking is the finding that the targeting domain is capable of increasing the activity of the therapeutic molecule. We have discovered that a vascular homing peptide for a tissue or lesion often also binds to the corresponding parenchymal cells. This is the case with CAR, which also recognizes the cells in the granulation tissue in wounds. This localization of the peptide receptor on the endothelial cells provokes the translocation of the blood vessel-bound peptide into the injured tissue, where the therapeutic payload can exert its functions more potently as it is anchored on the target cells in the parenchyma. We were able to show that the anchorage to target cells (outside of endothelial cells) provided by CAR peptide fused decorin, enhanced decorin's biological potency against transforming growth factor- $\beta$ (TGF- $\beta$ ). Later, Hubbell et al. engineered "super" growth factors that are more potent than the native ones, simply by fusing the growth factors with the heparinbinding domain of BMP2 (analogous to the CAR peptide being homologous to BMP4 heparin-binding domain) ${ }^{7}$.

One of the advantages of using short peptides as targeting elements, is that their small size is unlikely to cause an immune reaction. They are only a fraction of the size of the highly variable complementary determining regions (CDRs) of therapeutic antibodies, which usually have an excellent drug safety and a low immunogenic potential ${ }^{11}$. Furthermore, homology analysis (by BLAST) of these short and stable cyclic peptides typically reveals a high homology to parts of native proteins that are highly conserved across a range of species (as for example for CRK and CAR) ${ }^{28}$. This would predict high tolerance of the peptide by the immune system.

These pharmacological properties highlight the importance of advancing multi-functional, systemically administered, target-seeking recombinant fusion proteins. However, unless the target of a homing peptide is known to be unimportant for function of the immune system, cell proliferation, 
angiogenesis, etc., one cannot rule out the possibility of adverse effects caused by high doses of a homing peptide binding to its target receptor. Thus, it is necessary to elucidate the target and mechanism of homing peptides, and to investigate their safety.

\section{Unconjugated delivery - Bystander effect}

The latest innovation to enhance therapeutic drug targeting is a tissue-penetrating transport system for certain targeting peptides, which does not require any physical conjugation between the therapeutic and targeting elements ${ }^{45-47}$. The essential features of this system called the "Bystander effect" (Figure 3) were first elucidated using a new RGD (RGD is an integrin binding sequence) peptide, termed iRGD because it internalizes into target cells ${ }^{45-47}$. Like conventional RGD peptides, iRGD accumulates at tumor vasculature where it binds to integrin, but it is then cleaved by a protease to unmask a second binding motif, a so-called CendR motif (consensus: $\mathbf{R} / \mathbf{K X X R / K}$ in the C-terminal end of the peptide after the cleavage) ${ }^{45-47}$. The CendR motif binds to neuropilin-1, which activates a transport tissue-penetration and cell internalization pathway ${ }^{45-47}$. As the CendR pathway is a bulk transport system, it will, once activated, sweep along (through cells) any molecule from large proteins to nanoparticles ("Bystander effect") present in the environment ${ }^{45-47}$ (Figure 3). Thus, the therapeutic molecule can be simply co-injected with the vascular iRGD homing peptide able to induce the bystander effect which will sweep the drug molecule into the target organ. Interestingly, even large recombinant proteins, such as antibodies, can be transported in target organ-specific fashion using vascular homing peptides capable of inducing the "Bystander effect" ${ }^{45-47}$ (Figure 3). 
We have recently found that the vascular homing peptide CAR, which does not contain a CendRsequence, is a very potent inducer of a bystander effect in pulmonary arterial hypertension (PAH) ${ }^{48}$ (Figure 4). Namely, the CAR peptide targets inflammatory vasculature in experimental models of PAH and penetrates to inflammatory lung parenchyma ${ }^{48,49}$. Remarkably, any vasodilator drug can become a target organ-specific vasodilator in that model of $\mathrm{PAH}^{48}$ (Figure 4). When a low dose of a vasodilator is co-injected with CAR peptide, the drug accumulates in the diseased lungs and lowers the hypertension selectively only in the pulmonary circulation, but does not affect the systemic circulation, i.e. no vasodilation occurs ${ }^{48}$. This effect presents a new paradigm in the treatment of $\mathrm{PAH}$, where the clinical application of new, potential therapeutic agents has generally been hampered by their systemic toxicity/adverse effects ${ }^{48}$ (Figure 4). Whether CAR- and CendR-peptides induce a bystander effect that may be applicable for therapeutic benefits in regenerative medicine, remains to be examined. But the capability of transporting such large proteins as antibodies, could open avenues for targeting therapeutic proteins to their intended target organ or tissue via the "Bystander effect" (Figure 4). 


\section{A}
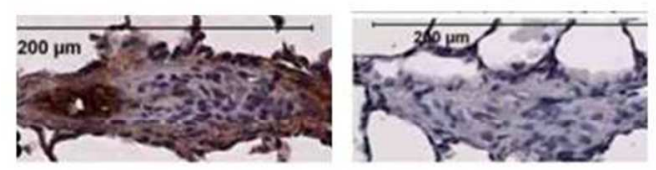

B
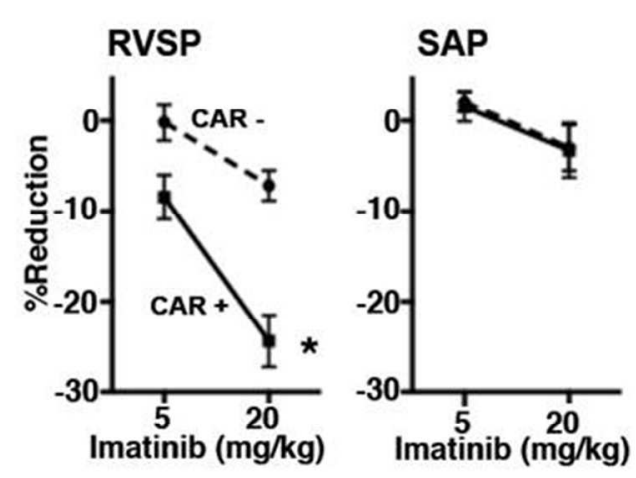

Pulmonary Arterial

Systemic Circulation :Hypertension (PAH)

C

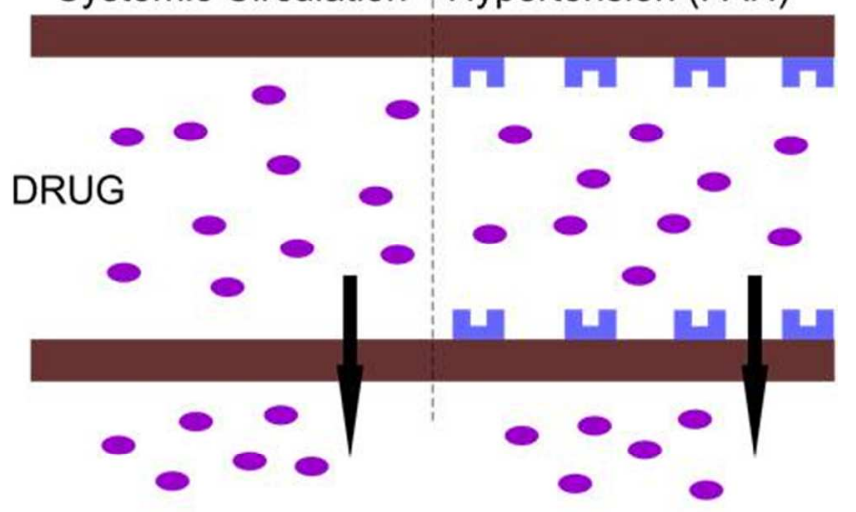

Pulmonary Arterial Systemic Circulation $:$ Hypertension (PAH)

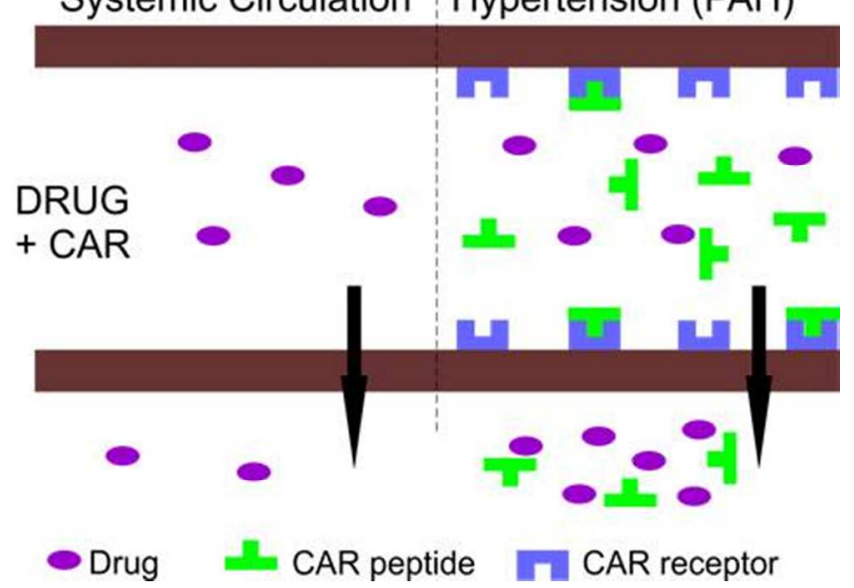

Figure 4. CAR peptide homes to inflammatory vasculature and induced target-tissue selective vasodilation in pulmonary arterial hypertension (PAH). (a) PAH was induced in rats by a single subcutaneous injection of SU5416 and 3 week exposure to hypoxia (10\% O2) followed by 6 weeks of normoxia ${ }^{48}$. CAR peptide accumulates in remodeled pulmonary arteries (A/C: occlusive neointimal formation) ${ }^{49}$. A small signal was detected in lung lesions of the PAH rats administered with CAR mutant peptide. (b) Effect of CAR $(0.3 \mathrm{mg} / \mathrm{kg})$ and of Rho-kinase inhibitor Y27632 (1 mg/kg) mixture on right ventricle (RVSP) and left ventricle LVSP systolic pressure. The CAR/Y27632 combination treatment induced a marked pulmonary-specific vasodilation RVSP with only a minimum effect on LVSP. When Y27632 or CAR was given alone at the same dose (1 
$\mathrm{mg} / \mathrm{kg}$ or $0.3 \mathrm{mg} / \mathrm{kg}$, respectively), a small effect was observed in RVSP and LVSP (data not shown). (c) Schematic illustration of targeted delivery by the "Bystander effect" induced by vascular homing peptide CAR.

\section{CAR-decorin - a target organ-specific, systemically administered, anti-fibrotic molecule}

Decorin (DCN) is the best characterized member of the small leucine rich proteoglycan (SLRP) family of extracellular matrix (ECM) proteins ${ }^{50}$. Due to its close interactions with collagen fibers in the ECM, i.e. DCN "decorates" collagen fibers, the proteoglycan was named decorin early on ${ }^{51}$. It has substantial interest to clinical medicine owing to its well established anti-fibrotic, anti-cancer and proregenerative effects ${ }^{50}$.

DCN was initially cloned in 1986 and thought at the time to be a structural constituent of the ECM ${ }^{51}$. However, soon it was established that DCN had a role beyond just a structural component of the ECM, as it became evident that it influenced cellular functions such as proliferation, spreading, migration and differentiation, as well as being a physiological regulator of inflammation ${ }^{52-54}$. Some of these early findings were derived from tumor cells, where it was shown that DCN inhibited cancer cell

proliferation and spreading ${ }^{52,55}$. These early studies as well as intensive research during past two decades have firmly established DCN as a tumor suppressor gene as well as a promising anti-tumor agent to treat human cancer patients ${ }^{50}$. 
Mammalian DCN contains a monomeric protein core of $42 \mathrm{kDa}$ and a single chondroitin/dermatan sulfate glycosaminoglycan (GAG) chain, attached to a serine residue near the $N$ terminus (Figure 5$)^{50}$. DCN exists as a dimer in physiological solutions and as a monomer when bound to collagen (Figure 5) ${ }^{56}$, and is the best characterized member of the growing family of SLRPs. Structurally, it has a domain of tandem leucine-rich repeats (LRRs, altogether 12 LRRs), flanked on both sides by two cysteine-rich regions (Figs. 5 \& 6$)^{50}$.

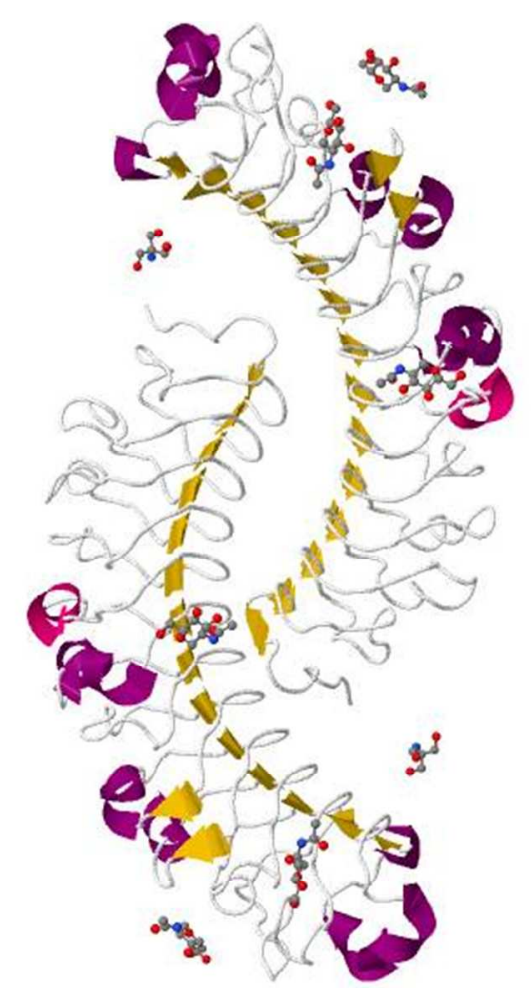

Figure 5. Structure of decorin. Mammalian decorin (DCN) contains a monomeric protein core of $42 \mathrm{kDa}$ and a single chondroitin/dermatan sulfate glycosaminoglycan (GAG) chain. DCN exists as a dimer in physiological solutions and is the best characterized member of the growing family of SLRPs. Structurally, it has a domain of tandem leucine-rich repeats (LRRs, altogether 12 LRRs), flanked on both sides by two cysteine-rich regions. Decorin dimer structure (from PDB 1XKU). 
Images prepared with JMOL program. The N-terminus is in the "middle" of the anti-parallel homodimer.

Anti-fibrotic function of DCN is related to it being a natural inhibitor of TGF- $\beta$ that shuts down the TGF- $\beta$ responses related to injury, cancer growth and inflammation $52,54,57,58$. The scar-inducing activities of TGF- $\beta 1$ in fibroblasts are mediated by connective tissue growth factor (CTGF/CCN2) and epidermal growth factor (EGF) family receptors (ERBBs) ${ }^{59}$. CCN2 activity requires the presence of EGF. Interestingly, DCN also neutralizes CCN2 ${ }^{60}$ and also EGF by binding to ERBBs ${ }^{61-63}$ (Figure 6). The active sites for TGF- $\beta$, CCN2, and EGF neutralization reside in different parts of the DCN molecule ${ }^{64}$. Thus, in theory, a single DCN molecule could simultaneously block multiple mediators of scarring ${ }^{64}$ (Figure 6). Moreover, DCN also inhibits myostatin ${ }^{65,66}$, an important contributor to scarring in some organs (Figure 6). Owing to this multifunctionality, DCN may be superior to therapeutic approaches that only inhibit TGF- ${ }^{64}$. The ability of recombinant DCN to prevent scar formation and fibrosis and to simultaneously promote tissue regeneration has been demonstrated in numerous experimental tissue injury- and disease-models ${ }^{50,54,57 .}$ 


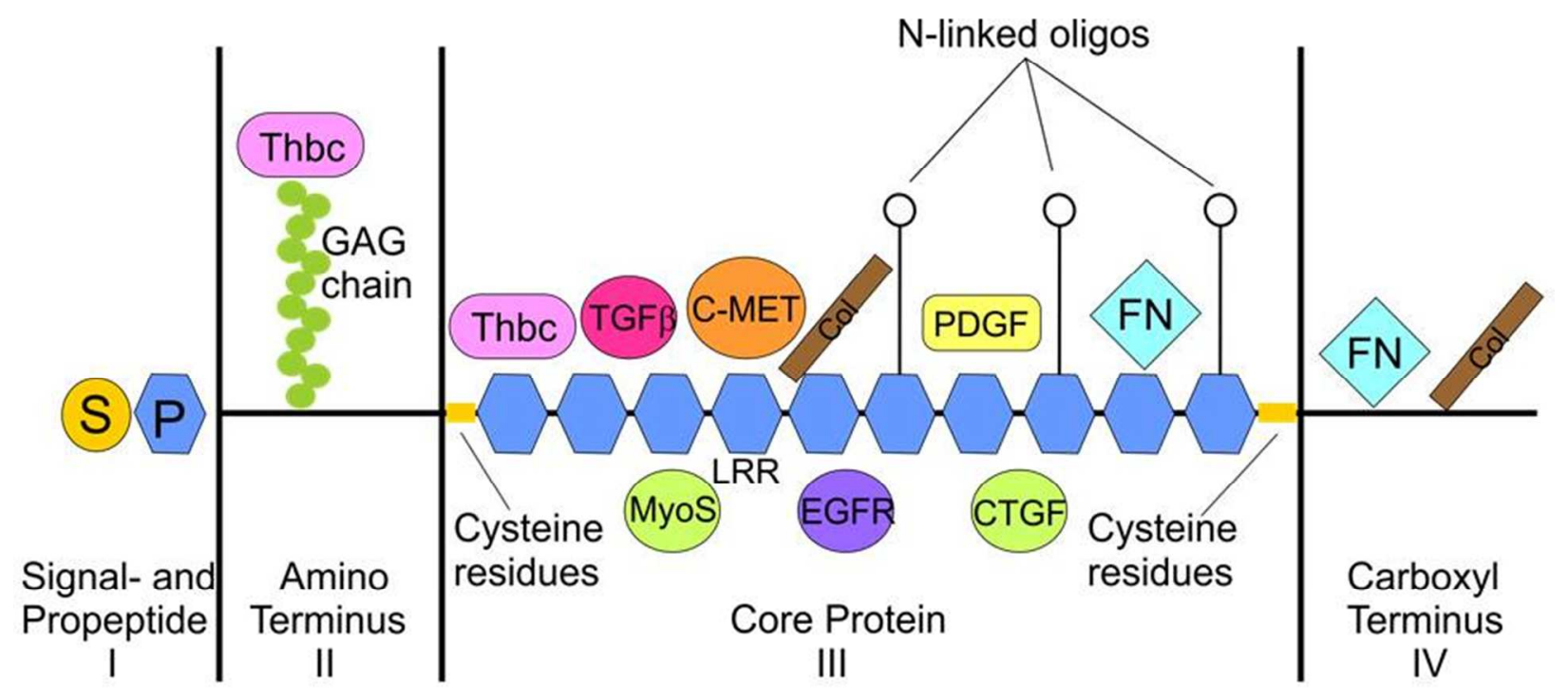

Mature Decorin (DCN) Protein

Figure 6. Decorin interacts with multiple growth factor signaling pathways crucial for cancer

growth. Schematic drawing of the molecular structure of decorin (DCN). All four domains I-IV of decorin core protein are indicated. DCN has a monomeric protein core and a single chondroitin/dermatan sulfate glycosaminoglycan (GAG) chain. Structurally, it has a domain of tandem leucine-rich repeats (LRR), flanked on both sides by two cysteine-rich regions. DCN interacts with a wide set of different signaling molecules, among them different isoforms of transforming growth factor- $\beta$ (TGF $\beta$ ), platelet-derived growth factor (PDGF), epidermal growth factor receptor (EGFR) and ErbB1 - 4 receptor tyrosine kinases, myostatin (MyoS), connective tissue growth factor/CCN2 (CTGF), thrombospondin (Thbs), collagen (Col) and fibronectin (FN), implicated in cancer progression. The active/binding sites of DCN for TGF- $\beta$, CCN2, c-Met and 
EGFR neutralization/binding all reside in different parts of the DCN molecule. Thus, in theory, a single DCN molecule could simultaneously sequester multiple important mediators of tumor growth and antagonize multiple signaling pathways crucial for tumor growth and progression. Thus, owing to this multi-functionality, DCN may exert its anti-cancer effects through multiple molecular approaches that all contribute to varying degree to its biological effects on cancer cells and tumor environment.

We have recently developed a systemically administered, targeted, e.g. inflammation- and angiogenesis-homing version of DCN core protein (Figure 7) ${ }^{42}$. The angiogenesis- and inflammationspecificity of this enhanced DCN core protein is achieved by a fusion to the CAR homing peptide that works as an address tag in the fusion protein and delivers systemically administered CAR-DCN to angiogenic and inflammatory vasculature (Figure 7) ${ }^{42}$. CAR-DCN peptide can deliver increased amounts of DCN in a tissue-specific manner with a significant therapeutic advantage over ordinary DCN core protein in healing skin wounds (Figure 7) ${ }^{42}$. Furthermore, the fusion of CAR to recombinant DCN enhances its neutralization activity of TGF- $\beta$ and provides the desired selectivity against the fibrotic isoforms of TGF- $\beta^{42}$. The molecular explanation for the enhanced biological activity of CARDCN is that the CAR peptide binds to HSPGs on the target cells. TGF- $\beta 1$, and TGF- $\beta 2$ in turn, also bind heparan sulfate and HSPG binding increases their biological activity (Figure 7) ${ }^{42,64}$. Thus, CAR mediated binding of CAR-DCN to HSPGs may enhance the neutralizing effect of the fusion protein by bringing it into the proximity of the HSPG-binding TGF- $\beta s^{42,64}$ (Figure 7). More recently, we have shown that CAR-DCN reduces the severity of abdominal aortic aneurysm. 

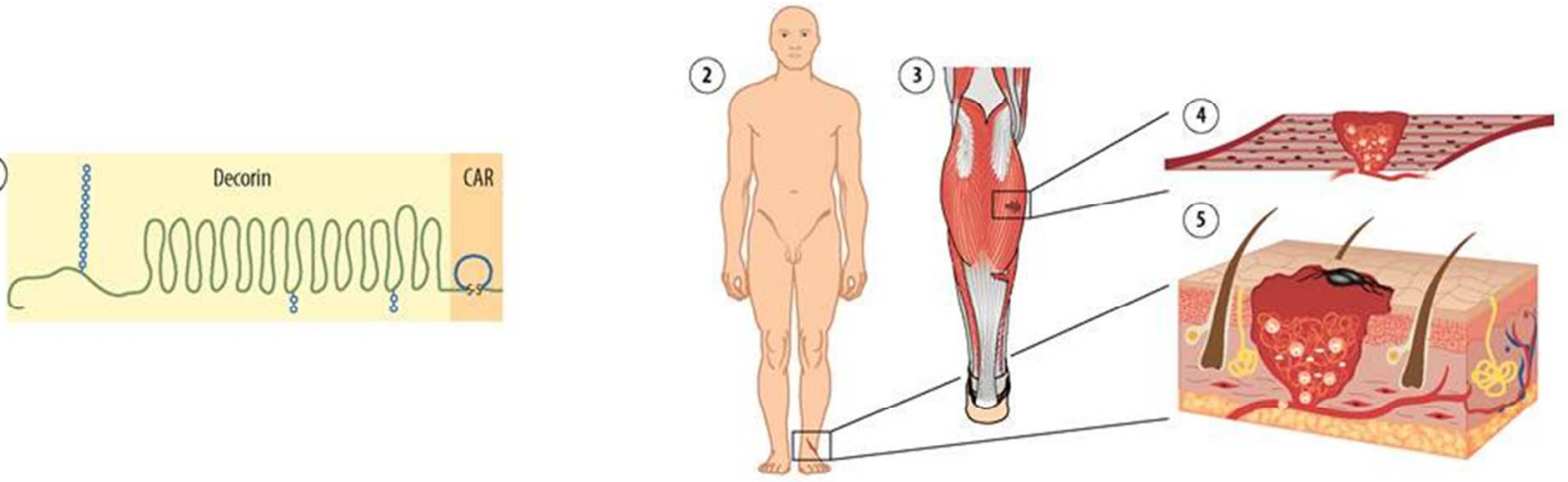

(6)
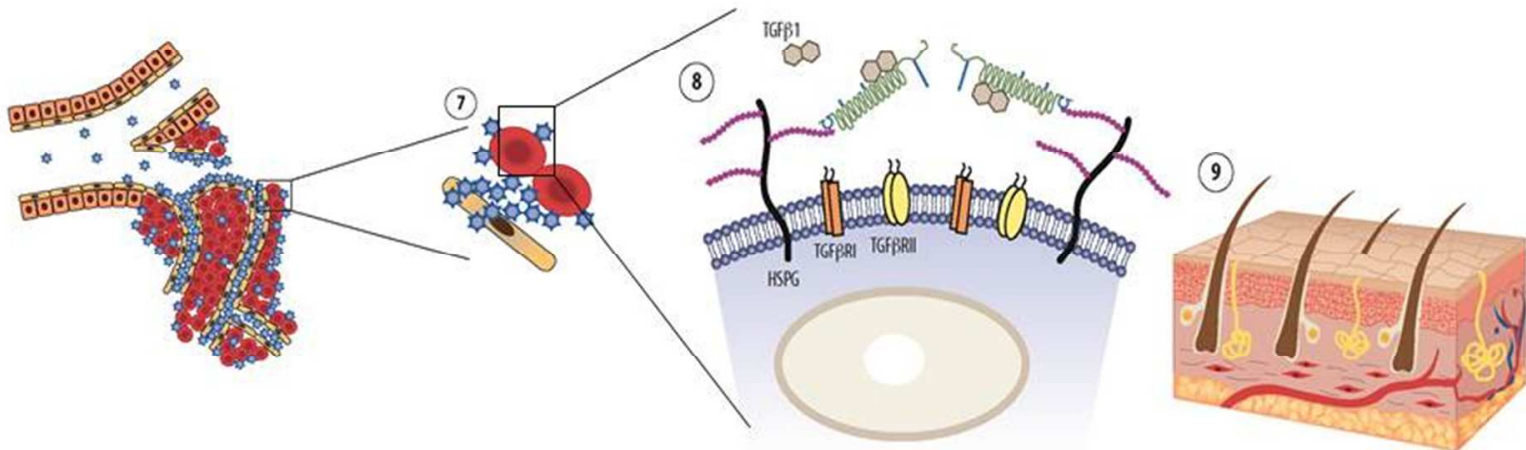

Figure 7. Schematic illustration of the mechanism of action of the systemically administered, target-organ specific anti-fibrotic molecule CAR-decorin. CAR-decorin (1) is a systemically administered, target-seeking, multi-functional biotherapeutic that inhibits scar formation. It can be targeted to an injury taking place at any organ of the body $(2,3)$ (or multiple organs simultaneously). The CAR homing peptide as part of the fusion protein targets angiogenic vasculature, which forms at the site of the injury $(4,5)$. The CAR peptide and any payload attached to it (Blue stars) then extravasates into surrounding tissue (6), where it binds to its receptor(s) on the cell surface of the scar producing fibroblasts (7). CAR binding to heparan sulfate proteoglycans (HSPGs) provides docking sites in the proximity of the main scar-inducing growth factors TGF- $\beta 1$ and TGF- $\beta 2$ (8) facilitating the neutralization of these growth factors by the therapeutic part of the molecule, decorin (8). This mechanism results in therapeutic response (9) seen as reduced scar formation in the skin. Picture by Helena Schmidt; reproduced 
with permission from Finnish Medical Journal Duodecim (originally published in Duodecim 2011;127:50-51).

\section{Targeting lung vasculature in PAH using nanoscale drug delivery systems}

Therapeutic delivery of drugs through the lungs for local bronchodilatory and anti-inflammatory effects is the most effective way of managing chronic inflammatory diseases- asthma and chronic obstructive pulmonary disorders (COPD) ${ }^{67}$. Lung delivery of therapeutic proteins, such as insulin, has also gained momentum in this decade ${ }^{68}$. A handful of studies have shown that pulmonary specific delivery of anti-PAH drugs could be a better alternative to the oral or intravenous therapies ${ }^{69-72}$. Different small or large molecules with therapeutic potential can be packaged into lipid or polymerbased nanocarriers which can be modified to offer advantages like prolongation of drug release, deep lung deposition for efficient drug absorption ${ }^{69-75}$. Moreover, by modifying the surface of the particles with CAR-peptide, those particles can be targeted to the diseased vasculature for selective effects ${ }^{70}$, ${ }^{72,74}$. In the present review, we have discussed the methods, advantages and future aspects of homing different inhalable nanocarriers towards the remodeled arteries by using CAR peptide for the treatment of pulmonary arterial hypertension (Figure 8). 


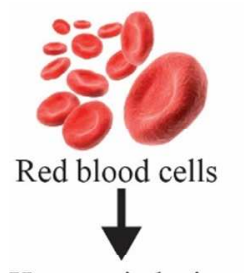

Hypotonic lysis Drug loading in erytrhocyte ghosts Extrusion and CAR peptide conjugation
Micelle preparation and drug loading

CAR peptide conjugation
Liposome preparation Drug loading

CAR peptide conjugation

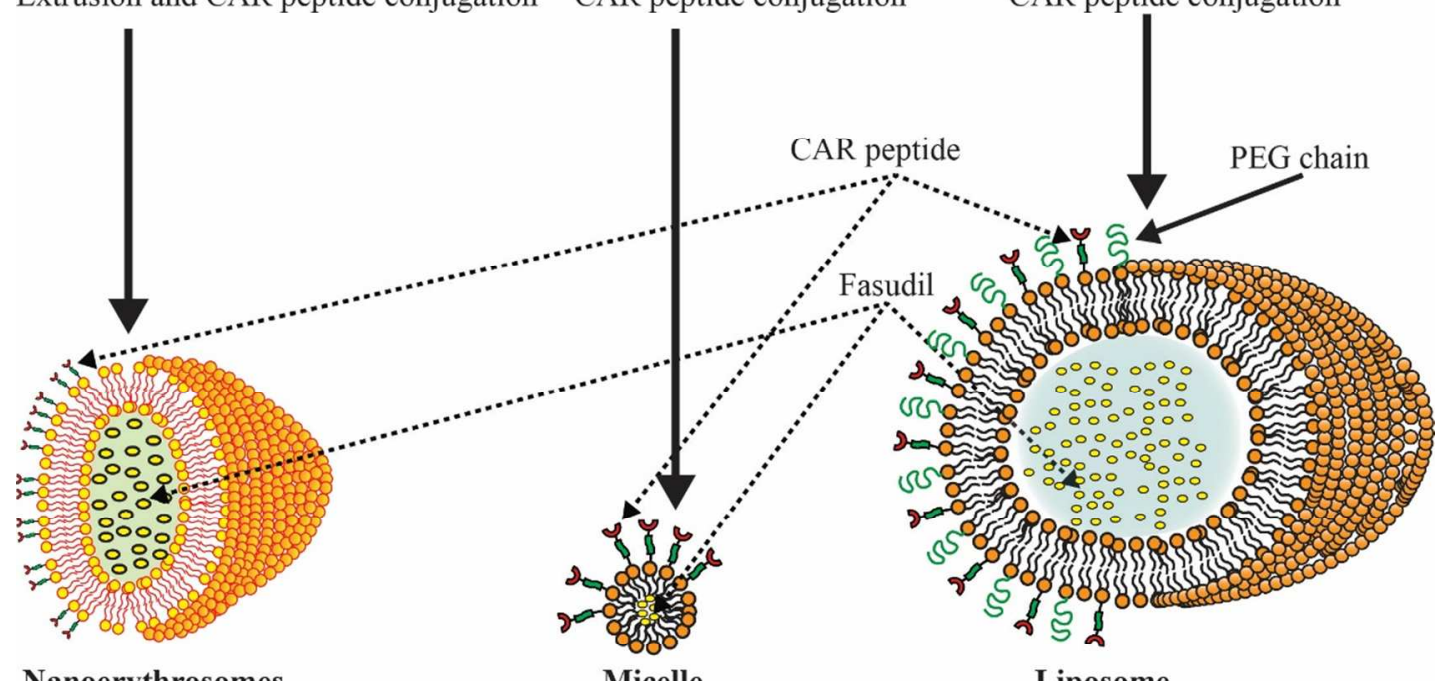

Nanoerythrosomes

Liposome

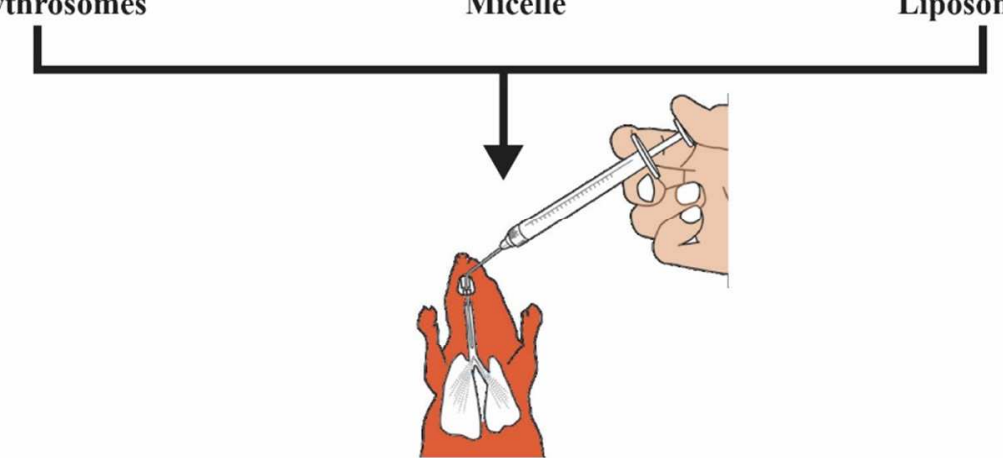

Intratracheal administration in PAH rats

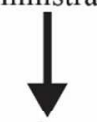

Hemodynamic measurement

- Selective and prolonged pulmonary arterial vasodilation

- Minimum effect on systemic pressure

Figure 8. Peptide-targeted pulmonary arterial homing approaches of different nanocarriers.

\section{PEG-polyethylene glycol.}




\section{Peptide-micelle conjugates}

Micelles, the donut-shaped nanostructures that are composed of amphiphilic block copolymers, are considered more stable than the liposomes, has higher drug entrapment capability and are small in size as low as $\sim 10 \mathrm{~nm}$. Polyethylene glycol-distearoyl-phosphoethanolamine (DSPE-PEG 5000 ), a copolymer that was used to encapsulate a number of drugs in micellar forms, has been used to prepare CAR-conjugated micelles of fasudil, an investigational vasodilator for $\mathrm{PAH}{ }^{70}$. The resultant peptide-micelles hybrid had aerodynamic properties suitable for deep-lung deposition and moderate drug entrapment efficiency. These CAR-modified micelles of fasudil was effectively taken up by the HSPGs expressing pulmonary arterial smooth muscle cells suggesting PAH vascular specific targeting. In-vivo absorption studies of these micelles suggests that the formulation extended the plasma halflife of the drug by $\sim 15$ times. CAR-micelles of fasudil were also found more selective in reducing mean pulmonary arterial pressure in monocrotaline-induced $\mathrm{PAH}$ rats than that of unmodified fasudil micelles, suggesting a strong diseased pulmonary artery specific targeting in $\mathrm{PAH}^{70}$.

\section{Peptide conjugated nanoerythrosomes}

Nanoerythrosomes (NERs) are the vesicles prepared by the extrusion of white unsealed red blood cell (RBC) ghosts. RBC ghosts are prepared by several round of hemolysis with hypotonic solutions. Derived from a biomimetic natural origin, NERs offer several advantages like lower propensity of forming aggregates, higher drug retention capacity and long circulation time. Conjugation of targeting moieties onto the surface of the NER is comparatively straight forward due to the abundance of amine groups on the surface of the NERs ${ }^{76,77}$. CAR-peptide conjugated NERs loaded with fasudil was respirable and was preferentially uptaken by the TGF- $\beta$ induced HSPGs expressing pulmonary arterial smooth muscle cells (PASMC) ${ }^{77}$. CAR-conjugated fasudil NERs, when administered intratracheally to 
the MCT induced PAH rats, showed pulmonary selective vasodilation with minimum perturbation on the systemic pressures as compared to that of the unmodified NER containing fasudil ${ }^{77}$. Upon pulmonary administration CAR conjugated fasudil NERs was twice more selective than the unmodified fasudil NERs as calculated by the lung targeting indices ${ }^{77}$. Overall, CAR-conjugated NERs can be used as a suitable targeted biomimetic system for delivering anti-PAH therapeutics to the diseased vasculature more efficiently.

\section{Peptide conjugated liposomes}

In last five decades, liposomes- the closed bilayered nanospheres composed of phospholipids- gained tremendous interest as a drug delivery system for encapsulating a diverse range of therapeutic small and large molecules that are distinct in terms of physicochemical properties ${ }^{78,79}$. These selfassembled nanocarriers can encapsulate both hydrophilic and hydrophobic drugs, offers several benefits such as good solubilization, colloidal, chemical and biological stability and scope of surface modification for targeting ${ }^{79,80}$. After pulmonary administration, CAR-peptide linked liposomal formulation of fasudil prolonged the drug half-life by 34-folds, can evade alveolar macrophage clearance, and was preferentially taken up by the TGF- $\beta$ activated PASMCs. Efficacy studies in PAH rats reveals that CAR-conjugated inhalable liposomes showed pulmonary-specific vasodilation as compared to that of the unmodified fasudil liposomes ${ }^{71}$. A separate study reports that two drugs, fasudil and a reactive oxygen species scavenger- super oxide dismutase (SOD), can also be encapsulated in the same liposome while retaining the CAR peptide attached on the surface ${ }^{72}$. This dual-drug approach with site-targeted liposomes has important clinical relevance as the development of PAH involves multiple pathobiological pathways and are usually managed different combination therapies. 


\section{Future challenges}

Although targeted nanocarriers showed good promise in producing selective anti-PAH effects in the diseased vasculature of the animals after single administration, thorough long-term safety and efficacy studies must be established before any clinical translation can be made. Steady-state pharmacokinetics of the drugs after repeated administration is needed to be correlated with pharmacodynamic effects. In case of combination therapies, potential pharmacokinetic and pharmacodynamic interactions are required to be investigated. PLGA-based solid microparticles are often preferred in designing inhalable therapeutics because of their trusted safety profile, superior biodegradability and biocompatibility, better stability for being in solid powder form and the flexibility of surface (stealthing) and core-modification (porosity) $69,73,81,82$ However, surface modification of PLGA-based nanospheres with peptides is challenging mostly because of protein/peptide denaturation in the harsh organic solvents that are used in particle preparation. Developing a proteinfriendly particle preparation technique with step-wise optimization and the selection of a suitable polymer might be helpful in developing a peptide-coated solid inhalable particles of anti-PAH drugs ${ }^{83}$.

\section{Acknowledgements}

The work was funded by the Sigrid Juselius Foundation, the Academy of Finland, Päivikki and Sakari Sohlberg Foundation, Instrumentarium Research Foundation, Tampere Tuberculosis Foundation, Pirkanmaa Hospital District Research Foundation and the Finnish Cultural Foundation. 


\section{Conflicts of Interest}

The authors declare no conflict of interest. 
References:

(1) Gurtner, G.C.; Werner, S.; Barrandon, Y.; Longaker, M.T. Wound repair and regeneration. Nature 2008, 453, 314-321, DOI: 10.1038/nature07039 [doi].

(2) Järvinen, T.A.; Järvinen, T.L.; Kääriäinen, M.; Kalimo, H.; Järvinen, M. Muscle injuries: biology and treatment. Am. J. Sports Med. 2005, 33, 745-764, DOI: 33/5/745 [pii].

(3) Eming, S.A.; Martin, P.; Tomic-Canic, M. Wound repair and regeneration: mechanisms, signaling, and translation. Sci. Transl. Med. 2014, 6, 265sr6, DOI: 10.1126/scitranslmed.3009337 [doi].

(4) Martino, M.M.; Briquez, P.S.; Maruyama, K.; Hubbell, J.A. Extracellular matrix-inspired growth factor delivery systems for bone regeneration. Adv. Drug Deliv. Rev. 2015, DOI: S0169409X(15)00063-0 [pii].

(5) Mitchell, A.C.; Briquez, P.S.; Hubbell, J.A.; Cochran, J.R. Engineering growth factors for regenerative medicine applications. Acta Biomater. 2016, 30, 1-12, DOI: 10.1016/j.actbio.2015.11.007 [doi].

(6) Geer, D.J.; Swartz, D.D.; Andreadis, S.T. Biomimetic delivery of keratinocyte growth factor upon cellular demand for accelerated wound healing in vitro and in vivo. Am. J. Pathol. 2005, 167, 1575-1586, DOI: S0002-9440(10)61242-4 [pii].

(7) Martino, M.M.; Briquez, P.S.; Guc, E.; Tortelli, F.; Kilarski, W.W.; Metzger, S.; Rice, J.J.; Kuhn, G.A.; Muller, R.; Swartz, M.A.; Hubbell, J.A. Growth factors engineered for super-affinity to the extracellular matrix enhance tissue healing. Science 2014, 343, 885-888, DOI: 10.1126/science.1247663 [doi].

(8) Arap, W.; Pasqualini, R.; Ruoslahti, E. Cancer treatment by targeted drug delivery to tumor vasculature in a mouse model. Science 1998, 279, 377-380.

(9) Hussain, S.; Rodriguez-Fernandez, M.; Braun, G.B.; Doyle, F.J.,3rd; Ruoslahti, E. Quantity and accessibility for specific targeting of receptors in tumours. Sci. Rep. 2014, 4, 5232, DOI: 10.1038/srep05232 [doi].

(10) Ruoslahti, E.; Rajotte, D. An address system in the vasculature of normal tissues and tumors. Annu. Rev. Immunol. 2000, 18, 813-827, DOI: 18/1/813 [pii].

(11) AlDeghaither, D.; Smaglo, B.G.; Weiner, L.M. Beyond peptides and mAbs--current status and future perspectives for biotherapeutics with novel constructs. J. Clin. Pharmacol. 2015, 55 Suppl 3, S4-20, DOI: 10.1002/jcph.407 [doi].

(12) Ruoslahti, E.; Bhatia, S.N.; Sailor, M.J. Targeting of drugs and nanoparticles to tumors. J. Cell Biol. 2010, 188, 759-768, DOI: 10.1083/jcb.200910104 [doi]. 
(13) Teesalu, T.; Sugahara, K.N.; Ruoslahti, E. Mapping of vascular ZIP codes by phage display. Methods Enzymol. 2012, 503, 35-56, DOI: 10.1016/B978-0-12-396962-0.00002-1 [doi].

(14) Huang, R.; Ma, H.; Guo, Y.; Liu, S.; Kuang, Y.; Shao, K.; Li, J.; Liu, Y.; Han, L.; Huang, S.; An, S.; Ye, L.; Lou, J.; Jiang, C. Angiopep-conjugated nanoparticles for targeted long-term gene therapy of Parkinson's disease. Pharm. Res. 2013, 30, 2549-2559, DOI: 10.1007/s11095-013-1005-8 [doi].

(15) Oh, P.; Borgstrom, P.; Witkiewicz, H.; Li, Y.; Borgstrom, B.J.; Chrastina, A.; Iwata, K.; Zinn, K.R.; Baldwin, R.; Testa, J.E.; Schnitzer, J.E. Live dynamic imaging of caveolae pumping targeted antibody rapidly and specifically across endothelium in the lung. Nat. Biotechnol. 2007, 25, 327337, DOI: nbt1292 [pii].

(16) Oh, P.; Testa, J.E.; Borgstrom, P.; Witkiewicz, H.; Li, Y.; Schnitzer, J.E. In vivo proteomic imaging analysis of caveolae reveals pumping system to penetrate solid tumors. Nat. Med. 2014, 20, 1062-1068, DOI: 10.1038/nm.3623 [doi].

(17) Ruoslahti, E. Vascular zip codes in angiogenesis and metastasis. Biochem. Soc. Trans. 2004, 32, 397-402, DOI: 10.1042/BST0320397 [doi].

(18) Rajotte, D.; Arap, W.; Hagedorn, M.; Koivunen, E.; Pasqualini, R.; Ruoslahti, E. Molecular heterogeneity of the vascular endothelium revealed by in vivo phage display. J. Clin. Invest. 1998, 102, 430-437, DOI: 10.1172/JCl3008 [doi].

(19) Nolan, D.J.; Ginsberg, M.; Israely, E.; Palikuqi, B.; Poulos, M.G.; James, D.; Ding, B.S.; Schachterle, W.; Liu, Y.; Rosenwaks, Z.; Butler, J.M.; Xiang, J.; Rafii, A.; Shido, K.; Rabbany, S.Y.; Elemento, O.; Rafii, S. Molecular signatures of tissue-specific microvascular endothelial cell heterogeneity in organ maintenance and regeneration. Dev. Cell. 2013, 26, 204-219, DOI:

10.1016/j.devcel.2013.06.017 [doi].

(20) Martin, P.; Nunan, R. Cellular and molecular mechanisms of repair in acute and chronic wound healing. Br. J. Dermatol. 2015, 173, 370-378, DOI: 10.1111/bjd.13954 [doi].

(21) Järvinen, M. Healing of a crush injury in rat striated muscle. 3. A micro-angiographical study of the effect of early mobilization and immobilization on capillary ingrowth. Acta Pathol. Microbiol. Scand. A. 1976, 84, 85-94.

(22) Järvinen, T.A.H.; May, U.; Prince, S. Systemically Administered, Target Organ-Specific Therapies for Regenerative Medicine. Int. J. Mol. Sci. 2015, 16, 23556-23571, DOI: 10.3390/ijms161023556 [doi].

(23) Yanez, C.O.; Morales, A.R.; Yue, X.; Urakami, T.; Komatsu, M.; Järvinen, T.A.; Belfield, K.D. Deep vascular imaging in wounds by two-photon fluorescence microscopy. PLoS One 2013, 8, e67559, DOI: 10.1371/journal.pone.0067559 [doi]. 
(24) Pasqualini, R.; Ruoslahti, E. Organ targeting in vivo using phage display peptide libraries. Nature 1996, 380, 364-366, DOI: 10.1038/380364a0 [doi].

(25) Järvinen, T.A. Design of target-seeking antifibrotic compounds. Methods Enzymol. 2012, 509, 243261, DOI: 10.1016/B978-0-12-391858-1.00013-7 [doi].

(26) Zhang, L.; Hoffman, J.A.; Ruoslahti, E. Molecular profiling of heart endothelial cells. Circulation 2005, 112, 1601-1611, DOI: CIRCULATIONAHA.104.529537 [pii].

(27) Pilch, J.; Brown, D.M.; Komatsu, M.; Järvinen, T.A.; Yang, M.; Peters, D.; Hoffman, R.M.; Ruoslahti, E. Peptides selected for binding to clotted plasma accumulate in tumor stroma and wounds. Proc. Natl. Acad. Sci. U. S. A. 2006, 103, 2800-2804, DOI: 0511219103 [pii].

(28) Järvinen, T.A.; Ruoslahti, E. Molecular changes in the vasculature of injured tissues. Am. J. Pathol. 2007, 171, 702-711, DOI: S0002-9440(10)62002-0 [pii].

(29) Whitney, M.A.; Crisp, J.L.; Nguyen, L.T.; Friedman, B.; Gross, L.A.; Steinbach, P.; Tsien, R.Y.; Nguyen, Q.T. Fluorescent peptides highlight peripheral nerves during surgery in mice. Nat. Biotechnol. 2011, 29, 352-356, DOI: 10.1038/nbt.1764 [doi].

(30) Sellers, D.L.; Bergen, J.M.; Johnson, R.N.; Back, H.; Ravits, J.M.; Horner, P.J.; Pun, S.H. Targeted axonal import (TAxl) peptide delivers functional proteins into spinal cord motor neurons after peripheral administration. Proc. Natl. Acad. Sci. U. S. A. 2016, 113, 2514-2519, DOI: 10.1073/pnas.1515526113 [doi].

(31) Mann, A.P.; Scodeller, P.; Hussain, S.; Joo, J.; Kwon, E.; Braun, G.B.; Molder, T.; She, Z.G.; Kotamraju, V.R.; Ranscht, B.; Krajewski, S.; Teesalu, T.; Bhatia, S.; Sailor, M.J.; Ruoslahti, E. A peptide for targeted, systemic delivery of imaging and therapeutic compounds into acute brain injuries. Nat. Commun. 2016, 7, 11980, DOI: 10.1038/ncomms11980 [doi].

(32) Agemy, L.; Sugahara, K.N.; Kotamraju, V.R.; Gujraty, K.; Girard, O.M.; Kono, Y.; Mattrey, R.F.; Park, J.H.; Sailor, M.J.; Jimenez, A.I.; Cativiela, C.; Zanuy, D.; Sayago, F.J.; Aleman, C.; Nussinov, R.; Ruoslahti, E. Nanoparticle-induced vascular blockade in human prostate cancer. Blood 2010, 116, 2847-2856, DOI: 10.1182/blood-2010-03-274258 [doi].

(33) Schwager, K.; Kaspar, M.; Bootz, F.; Marcolongo, R.; Paresce, E.; Neri, D.; Trachsel, E. Preclinical characterization of DEKAVIL (F8-IL10), a novel clinical-stage immunocytokine which inhibits the progression of collagen-induced arthritis. Arthritis Res. Ther. 2009, 11, R142, DOI: 10.1186/ar2814 [doi].

(34) Galeazzi, M.; Bazzichi, L.; Sebastiani, G.D.; Neri, D.; Garcia, E.; Ravenni, N.; Giovannoni, L.; Wilton, J.; Bardelli, M.; Baldi, C.; Selvi, E.; Iluliano, A.; Minisola, G.; Caporali, R.; Prisco, E.; Bombardieri, S. A phase IB clinical trial with Dekavil (F8-IL10), an immunoregulatory 'armed antibody' for the 
treatment of rheumatoid arthritis, used in combination wilh methotrexate. Isr. Med. Assoc. J. 2014, 16, 666.

(35) Doll, F.; Schwager, K.; Hemmerle, T.; Neri, D. Murine analogues of etanercept and of F8-IL10 inhibit the progression of collagen-induced arthritis in the mouse. Arthritis Res. Ther. 2013, 15, R138, DOI: 10.1186/ar4319 [doi].

(36) Franz, M.; Doll, F.; Grun, K.; Richter, P.; Kose, N.; Ziffels, B.; Schubert, H.; Figulla, H.R.; Jung, C.; Gummert, J.; Renner, A.; Neri, D.; Berndt, A. Targeted delivery of interleukin-10 to chronic cardiac allograft rejection using a human antibody specific to the extra domain A of fibronectin. Int. J. Cardiol. 2015, 195, 311-322, DOI: 10.1016/j.ijcard.2015.05.144 [doi].

(37) Corti, A.; Curnis, F. Tumor vasculature targeting through NGR peptide-based drug delivery systems. Curr. Pharm. Biotechnol. 2011, 12, 1128-1134, DOI: BSP/CPB/E-Pub/000171-12-11 [pii].

(38) Calcinotto, A.; Grioni, M.; Jachetti, E.; Curnis, F.; Mondino, A.; Parmiani, G.; Corti, A.; Bellone, M. Targeting TNF-alpha to neoangiogenic vessels enhances lymphocyte infiltration in tumors and increases the therapeutic potential of immunotherapy. J. Immunol. 2012, 188, 2687-2694, DOI: 10.4049/jimmunol.1101877 [doi].

(39) Cardo-Vila, M.; Marchio, S.; Sato, M.; Staquicini, F.I.; Smith, T.L.; Bronk, J.K.; Yin, G.; Zurita, A.J.; Sun, M.; Behrens, C.; Sidman, R.L.; Lee, J.J.; Hong, W.K.; Wistuba, I.I.; Arap, W.; Pasqualini, R. Interleukin-11 Receptor Is a Candidate Target for Ligand-Directed Therapy in Lung Cancer: Analysis of Clinical Samples and BMTP-11 Preclinical Activity. Am. J. Pathol. 2016, 186, 21622170, DOI: 10.1016/j.ajpath.2016.04.013 [doi].

(40) Johansson-Percival, A.; Li, Z.J.; Lakhiani, D.D.; He, B.; Wang, X.; Hamzah, J.; Ganss, R. Intratumoral LIGHT Restores Pericyte Contractile Properties and Vessel Integrity. Cell. Rep. 2015, 13, 26872698, DOI: 10.1016/j.celrep.2015.12.004 [doi].

(41) Kean, T.J.; Duesler, L.; Young, R.G.; Dadabayev, A.; Olenyik, A.; Penn, M.; Wagner, J.; Fink, D.J.; Caplan, A.I.; Dennis, J.E. Development of a peptide-targeted, myocardial ischemia-homing, mesenchymal stem cell. J. Drug Target. 2012, 20, 23-32, DOI: 10.3109/1061186X.2011.622398 [doi].

(42) Järvinen, T.A.; Ruoslahti, E. Target-seeking antifibrotic compound enhances wound healing and suppresses scar formation in mice. Proc. Natl. Acad. Sci. U. S. A. 2010, 107, 21671-21676, DOI: 10.1073/pnas.1016233107 [doi].

(43) Ma, W.; Cai, S.; Du, J.; Tan, Y.; Chen, H.; Guo, Z.; Hu, H.; Fang, R.; Cai, S. SDF-1/54-DCN: a novel recombinant chimera with dual inhibitory effects on proliferation and chemotaxis of tumor cells. Biol. Pharm. Bull. 2008, 31, 1086-1091, DOI: JST.JSTAGE/bpb/31.1086 [pii]. 
(44) Kean, T.J.; Lin, P.; Caplan, A.I.; Dennis, J.E. MSCs: Delivery Routes and Engraftment, Cell-Targeting Strategies, and Immune Modulation. Stem Cells Int. 2013, 2013, 732742, DOI:

10.1155/2013/732742 [doi].

(45) Teesalu, T.; Sugahara, K.N.; Kotamraju, V.R.; Ruoslahti, E. C-end rule peptides mediate neuropilin1-dependent cell, vascular, and tissue penetration. Proc. Natl. Acad. Sci. U. S. A. 2009, 106, 16157-16162, DOI: 10.1073/pnas.0908201106 [doi].

(46) Sugahara, K.N.; Teesalu, T.; Karmali, P.P.; Kotamraju, V.R.; Agemy, L.; Greenwald, D.R.; Ruoslahti, E. Coadministration of a tumor-penetrating peptide enhances the efficacy of cancer drugs. Science 2010, 328, 1031-1035, DOI: 10.1126/science.1183057 [doi].

(47) Sugahara, K.N.; Teesalu, T.; Karmali, P.P.; Kotamraju, V.R.; Agemy, L.; Girard, O.M.; Hanahan, D.; Mattrey, R.F.; Ruoslahti, E. Tissue-penetrating delivery of compounds and nanoparticles into tumors. Cancer. Cell. 2009, 16, 510-520, DOI: 10.1016/j.ccr.2009.10.013 [doi].

(48) Toba, M.; Alzoubi, A.; O'Neill, K.; Abe, K.; Urakami, T.; Komatsu, M.; Alvarez, D.; Jarvinen, T.A.; Mann, D.; Ruoslahti, E.; McMurtry, I.F.; Oka, M. A novel vascular homing peptide strategy to selectively enhance pulmonary drug efficacy in pulmonary arterial hypertension. Am. J. Pathol. 2014, 184, 369-375, DOI: 10.1016/j.ajpath.2013.10.008 [doi].

(49) Urakami, T.; Järvinen, T.A.; Toba, M.; Sawada, J.; Ambalavanan, N.; Mann, D.; McMurtry, I.; Oka, M.; Ruoslahti, E.; Komatsu, M. Peptide-directed highly selective targeting of pulmonary arterial hypertension. Am. J. Pathol. 2011, 178, 2489-2495, DOI: 10.1016/j.ajpath.2011.02.032 [doi].

(50) Järvinen, T.A.; Prince, S. Decorin: A Growth Factor Antagonist for Tumor Growth Inhibition. Biomed. Res. Int. 2015, 2015, 654765, DOI: 10.1155/2015/654765 [doi].

(51) Krusius, T.; Ruoslahti, E. Primary structure of an extracellular matrix proteoglycan core protein deduced from cloned cDNA. Proc. Natl. Acad. Sci. U. S. A. 1986, 83, 7683-7687.

(52) Yamaguchi, Y.; Mann, D.M.; Ruoslahti, E. Negative regulation of transforming growth factor-beta by the proteoglycan decorin. Nature 1990, 346, 281-284, DOI: 10.1038/346281a0 [doi].

(53) Yamaguchi, Y.; Ruoslahti, E. Expression of human proteoglycan in Chinese hamster ovary cells inhibits cell proliferation. Nature 1988, 336, 244-246, DOI: 10.1038/336244a0 [doi].

(54) Border, W.A.; Noble, N.A.; Yamamoto, T.; Harper, J.R.; Yamaguchi, Y.; Pierschbacher, M.D.; Ruoslahti, E. Natural inhibitor of transforming growth factor-beta protects against scarring in experimental kidney disease. Nature 1992, 360, 361-364, DOI: 10.1038/360361a0 [doi].

(55) Ruoslahti, E.; Yamaguchi, Y. Proteoglycans as modulators of growth factor activities. Cell 1991, 64, 867-869, DOI: 0092-8674(91)90308-L [pii]. 
(56) Scott, P.G.; McEwan, P.A.; Dodd, C.M.; Bergmann, E.M.; Bishop, P.N.; Bella, J. Crystal structure of the dimeric protein core of decorin, the archetypal small leucine-rich repeat proteoglycan. Proc. Natl. Acad. Sci. U. S. A. 2004, 101, 15633-15638, DOI: 0402976101 [pii].

(57) Border, W.A.; Ruoslahti, E. Transforming growth factor-beta in disease: the dark side of tissue repair. J. Clin. Invest. 1992, 90, 1-7, DOI: 10.1172/JCI115821 [doi].

(58) Hildebrand, A.; Romaris, M.; Rasmussen, L.M.; Heinegard, D.; Twardzik, D.R.; Border, W.A.; Ruoslahti, E. Interaction of the small interstitial proteoglycans biglycan, decorin and fibromodulin with transforming growth factor beta. Biochem. J. 1994, 302 ( Pt 2), 527-534.

(59) Andrianifahanana, M.; Wilkes, M.C.; Gupta, S.K.; Rahimi, R.A.; Repellin, C.E.; Edens, M.; Wittenberger, J.; Yin, X.; Maidl, E.; Becker, J.; Leof, E.B. Profibrotic TGFbeta responses require the cooperative action of PDGF and ErbB receptor tyrosine kinases. FASEB J. 2013, 27, 4444-4454, DOI: $10.1096 / f j .12-224907$ [doi].

(60) Vial, C.; Gutierrez, J.; Santander, C.; Cabrera, D.; Brandan, E. Decorin interacts with connective tissue growth factor (CTGF)/CCN2 by LRR12 inhibiting its biological activity. J. Biol. Chem. 2011, 286, 24242-24252, DOI: 10.1074/jbc.M110.189365 [doi].

(61) Csordas, G.; Santra, M.; Reed, C.C.; Eichstetter, I.; McQuillan, D.J.; Gross, D.; Nugent, M.A.; Hajnoczky, G.; lozzo, R.V. Sustained down-regulation of the epidermal growth factor receptor by decorin. A mechanism for controlling tumor growth in vivo. J. Biol. Chem. 2000, 275, 3287932887, DOI: 10.1074/jbc.M005609200 [doi].

(62) Iozzo, R.V.; Moscatello, D.K.; McQuillan, D.J.; Eichstetter, I. Decorin is a biological ligand for the epidermal growth factor receptor. J. Biol. Chem. 1999, 274, 4489-4492, DOI:

10.1074/jbc.274.8.4489.

(63) Moscatello, D.K.; Santra, M.; Mann, D.M.; McQuillan, D.J.; Wong, A.J.; lozzo, R.V. Decorin suppresses tumor cell growth by activating the epidermal growth factor receptor. J. Clin. Invest. 1998, 101, 406-412, DOI: 10.1172/JCl846 [doi].

(64) Järvinen, T.A.; Ruoslahti, E. Targeted Antiscarring Therapy for Tissue Injuries. Adv. Wound. Care. (New Rochelle) 2013, 2, 50-54, DOI: 10.1089/wound.2011.0299 [doi].

(65) Miura, T.; Kishioka, Y.; Wakamatsu, J.; Hattori, A.; Hennebry, A.; Berry, C.J.; Sharma, M.; Kambadur, R.; Nishimura, T. Decorin binds myostatin and modulates its activity to muscle cells. Biochem. Biophys. Res. Commun. 2006, 340, 675-680, DOI: S0006-291X(05)02807-X [pii].

(66) Zhu, J.; Li, Y.; Shen, W.; Qiao, C.; Ambrosio, F.; Lavasani, M.; Nozaki, M.; Branca, M.F.; Huard, J. Relationships between transforming growth factor-beta1, myostatin, and decorin: implications for skeletal muscle fibrosis. J. Biol. Chem. 2007, 282, 25852-25863, DOI: M704146200 [pii]. 
(67) Miller-Larsson, A.; Selroos, O. Advances in asthma and COPD treatment: combination therapy with inhaled corticosteroids and long-acting beta 2-agonists. Curr. Pharm. Des. 2006, 12, 32613279, DOI: 10.2174/138161206778194187.

(68) Rashid, J.; Absar, S.; Nahar, K.; Gupta, N.; Ahsan, F. Newer devices and improved formulations of inhaled insulin. Expert Opin. Drug Deliv. 2015, 12, 917-928, DOI: 10.1517/17425247.2015.990436 [doi].

(69) Gupta, V.; Gupta, N.; Shaik, I.H.; Mehvar, R.; Nozik-Grayck, E.; McMurtry, I.F.; Oka, M.; Komatsu, M.; Ahsan, F. Inhaled PLGA particles of prostaglandin $E(1)$ ameliorate symptoms and progression of pulmonary hypertension at a reduced dosing frequency. Mol. Pharm. 2013, 10, 1655-1667, DOI: $10.1021 / \mathrm{mp} 300426$ [doi].

(70) Gupta, N.; Ibrahim, H.M.; Ahsan, F. Peptide-micelle hybrids containing fasudil for targeted delivery to the pulmonary arteries and arterioles to treat pulmonary arterial hypertension. $J$. Pharm. Sci. 2014, 103, 3743-3753, DOI: 10.1002/jps.24193 [doi].

(71) Nahar, K.; Absar, S.; Gupta, N.; Kotamraju, V.R.; McMurtry, I.F.; Oka, M.; Komatsu, M.; NozikGrayck, E.; Ahsan, F. Peptide-coated liposomal fasudil enhances site specific vasodilation in pulmonary arterial hypertension. Mol. Pharm. 2014, 11, 4374-4384, DOI: 10.1021/mp500456k [doi].

(72) Gupta, N.; Al-Saikhan, F.I.; Patel, B.; Rashid, J.; Ahsan, F. Fasudil and SOD packaged in peptidestudded-liposomes: Properties, pharmacokinetics and ex-vivo targeting to isolated perfused rat lungs. Int. J. Pharm. 2015, 488, 33-43, DOI: 10.1016/j.ijpharm.2015.04.031 [doi].

(73) Gupta, V.; Ahsan, F. Influence of PEI as a core modifying agent on PLGA microspheres of PGE(1), a pulmonary selective vasodilator. Int. J. Pharm. 2011, 413, 51-62, DOI:

10.1016/j.ijpharm.2011.04.017 [doi].

(74) Gupta, N.; Patel, B.; Nahar, K.; Ahsan, F. Cell permeable peptide conjugated nanoerythrosomes of fasudil prolong pulmonary arterial vasodilation in PAH rats. Eur. J. Pharm. Biopharm. 2014, 88, 1046-1055, DOI: S0939-6411(14)00311-7 [pii].

(75) Nahar, K.; Absar, S.; Patel, B.; Ahsan, F. Starch-coated magnetic liposomes as an inhalable carrier for accumulation of fasudil in the pulmonary vasculature. Int. J. Pharm. 2014, 464, 185-195, DOI: 10.1016/j.ijpharm.2014.01.007 [doi].

(76) Hamidi, M.; Zarrin, A.; Foroozesh, M.; Mohammadi-Samani, S. Applications of carrier erythrocytes in delivery of biopharmaceuticals. J. Control. Release 2007, 118, 145-160, DOI: S01683659(06)00708-5 [pii]. 
(77) Gupta, N.; Patel, B.; Ahsan, F. Nano-engineered erythrocyte ghosts as inhalational carriers for delivery of fasudil: preparation and characterization. Pharm. Res. 2014, 31, 1553-1565, DOI: 10.1007/s11095-013-1261-7 [doi].

(78) Torchilin, V.P. Recent advances with liposomes as pharmaceutical carriers. Nat. Rev. Drug Discov. 2005, 4, 145-160, DOI: nrd1632 [pii].

(79) Allen, T.M.; Cullis, P.R. Liposomal drug delivery systems: from concept to clinical applications. Adv. Drug Deliv. Rev. 2013, 65, 36-48, DOI: 10.1016/j.addr.2012.09.037 [doi].

(80) Maruyama, K. Intracellular targeting delivery of liposomal drugs to solid tumors based on EPR effects. Adv. Drug Deliv. Rev. 2011, 63, 161-169, DOI: 10.1016/j.addr.2010.09.003 [doi].

(81) Patel, B.; Gupta, V.; Ahsan, F. PEG-PLGA based large porous particles for pulmonary delivery of a highly soluble drug, low molecular weight heparin. J. Control. Release 2012, 162, 310-320, DOI: 10.1016/j.jconrel.2012.07.003 [doi].

(82) Yang, Y.; Bajaj, N.; Xu, P.; Ohn, K.; Tsifansky, M.D.; Yeo, Y. Development of highly porous large PLGA microparticles for pulmonary drug delivery. Biomaterials 2009, 30, 1947-1953, DOI: 10.1016/j.biomaterials.2008.12.044 [doi].

(83) Bilati, U.; Allemann, E.; Doelker, E. Strategic approaches for overcoming peptide and protein instability within biodegradable nano- and microparticles. Eur. J. Pharm. Biopharm. 2005, 59, 375-388, DOI: S0939-6411(04)00287-5 [pii]. 
Table of Contents graphic (TOC)

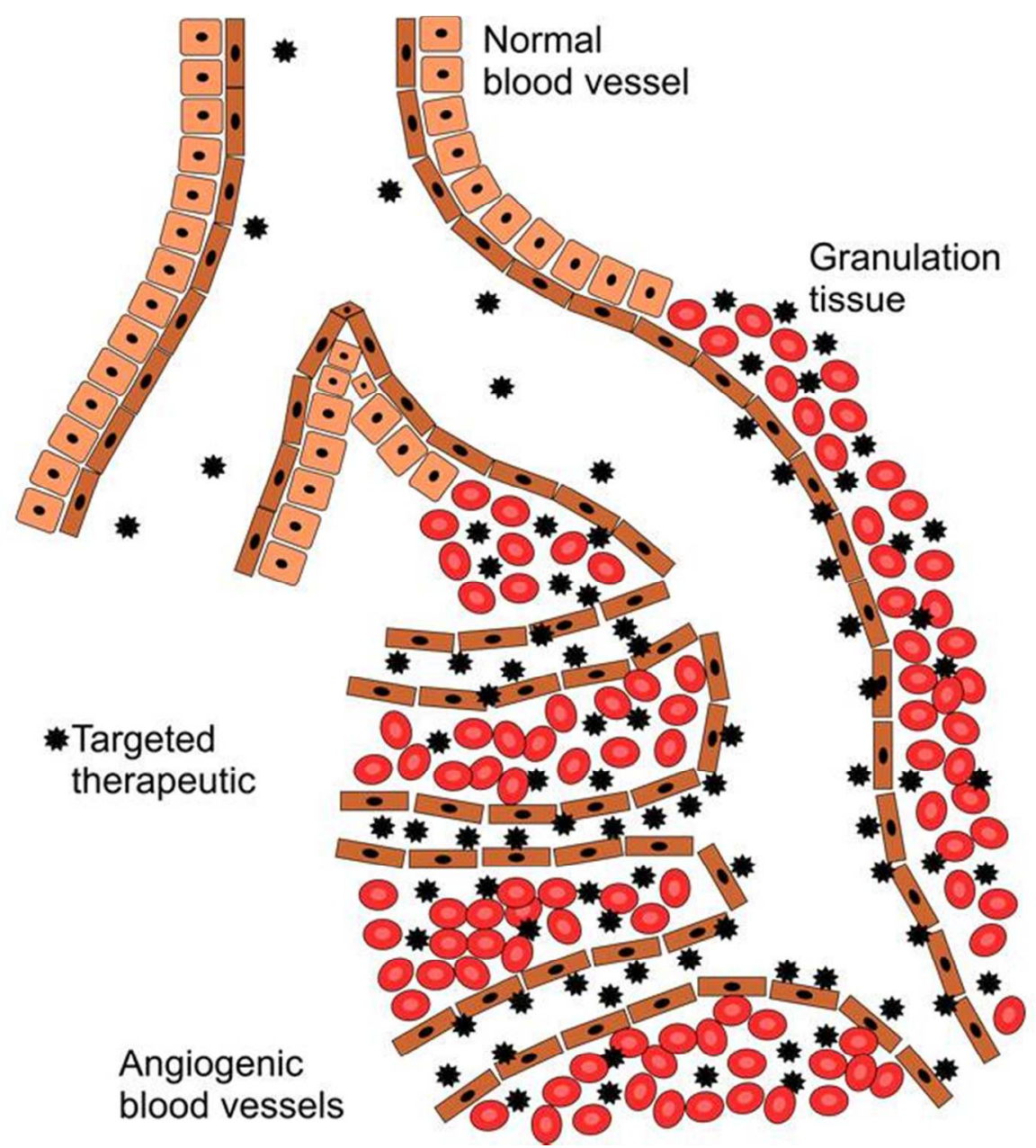




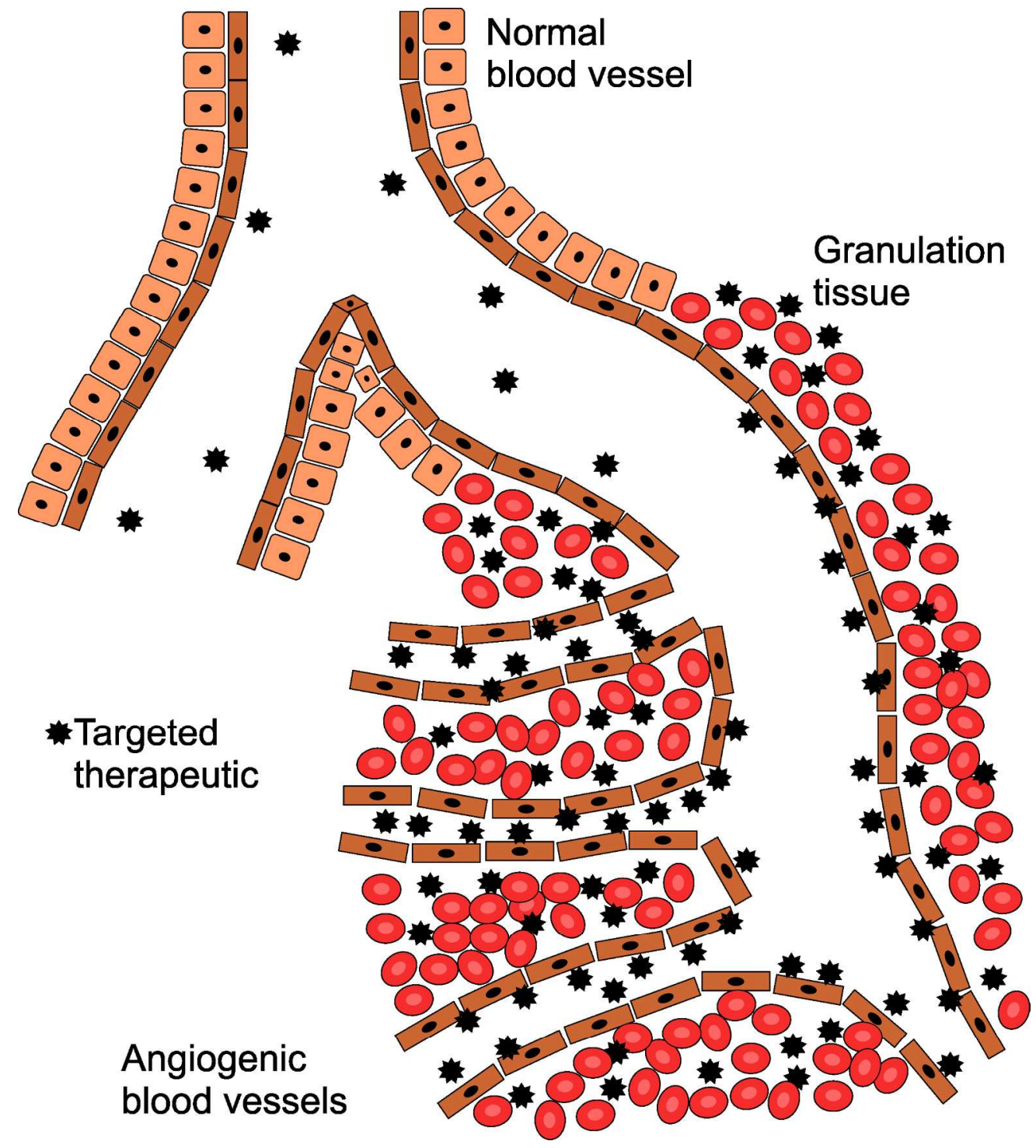

Figure 1. Target-specific drug therapies in tissue regeneration. Molecular "Zip/postal codes" in the angiogenic vasculature of the regenerating tissues allow target organ-specific delivery of the systemically administered therapeutic recombinant proteins by affinity-based physical targeting (using peptides or antibodies as an "address tag") to injured tissues undergoing repair. The desired outcome of the targeted therapies is similar to topical application: increased local accumulation of the recombinant protein in the target tissue and lower systemic concentration of the therapeutic payload. 
Figure 2. Schematic presentation of the principle of in vivo phage display. (a) A cyclic CX7C-peptide library has been cloned to the C-terminus of the phage coat protein and expressed in 415 copies in T7 Select 415 $1 \mathrm{~b}$ phage. (b) A phage library is injected into circulation. The homing peptides on the phage surface bind to endothelium in the tissues, resulting in an enrichment of phages bound to the endothelium of the target tissue. Target tissue is homogenized, cell suspensions prepared, and the bound phage rescued and amplified by adding E. coli. The amplified phage pool recovered from the target tissue is then re-injected into mice at a similar disease stage, and the screening cycle is repeated several times to ensure that phage clones that specifically bind (i.e. home) towards target will be recovered. A set of phage clones is randomly collected from a homing phage population that shows enriched homing towards target tissue. The peptide-encoding DNA inserts are amplified by PCR, and the PCR products sequenced. 


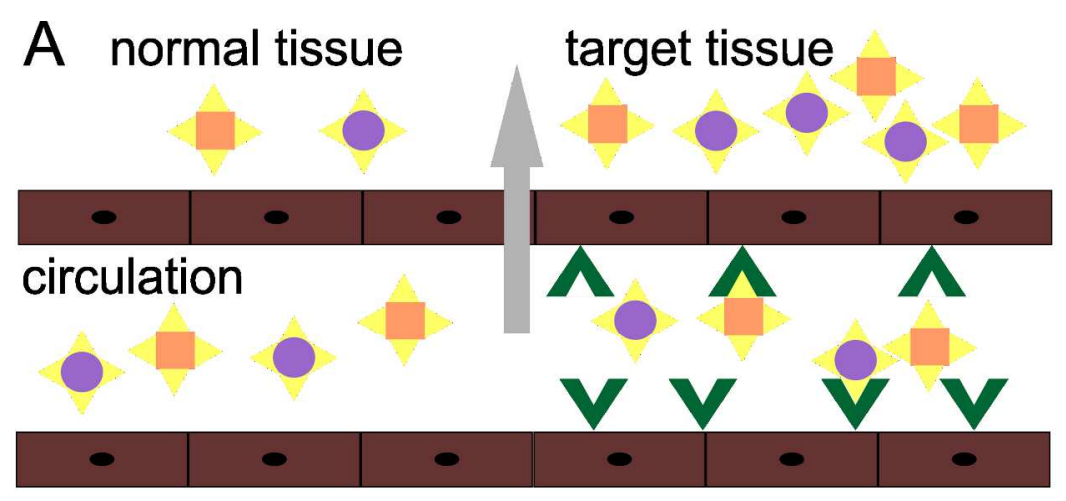

\section{B normal tissue}

\section{target tissue}

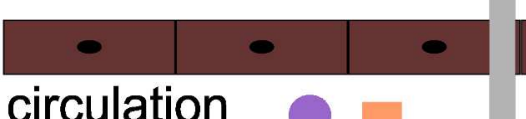

\section{circulation}

Figure 3. Systemically administered, targeted therapies. (a) Conjugated delivery. The drugs are physically conjugated to the targeting element in conventional drug targeting. For protein-based therapeutics, targeting domain and therapeutic molecule are fused together as a recombinant protein with enhanced activity and tissue-specificity. (b) - (c) Bystander effect. Therapeutic drug(s) co-injected with tissuepenetrating targeting peptides are transported across the vessel wall and through tissue together with the peptides. No actual physical connection is needed between them; the cell penetrating homing peptide "sweeps" co-injected drug(s) to its target (homing) tissue in a tissue-specific fashion.

$$
188 \times 267 \mathrm{~mm} \text { ( } 300 \times 300 \text { DPI) }
$$


Figure 4. CAR peptide homes to inflammatory vasculature and induced target-tissue selective vasodilation in pulmonary arterial hypertension (PAH). (a) PAH was induced in rats by a single subcutaneous injection of SU5416 and 3 week exposure to hypoxia ( $10 \%$ O2) followed by 6 weeks of normoxia 48 . CAR peptide accumulates in remodeled pulmonary arteries (A/C: occlusive neointimal formation) 49. A small signal was detected in lung lesions of the PAH rats administered with CAR mutant peptide. (b) Effect of CAR (0.3 $\mathrm{mg} / \mathrm{kg})$ and of Rho-kinase inhibitor $Y 27632(1 \mathrm{mg} / \mathrm{kg})$ mixture on right ventricle (RVSP) and left ventricle LVSP systolic pressure. The CAR/Y27632 combination treatment induced a marked pulmonary-specific vasodilation RVSP with only a minimum effect on LVSP. When Y27632 or CAR was given alone at the same dose $(1 \mathrm{mg} / \mathrm{kg}$ or $0.3 \mathrm{mg} / \mathrm{kg}$, respectively), a small effect was observed in RVSP and LVSP (data not shown). (c) Schematic illustration of targeted delivery by the "Bystander effect" induced by vascular homing peptide CAR. 
Figure 5. Structure of decorin. Mammalian decorin (DCN) contains a monomeric protein core of $42 \mathrm{kDa}$ and a single chondroitin/dermatan sulfate glycosaminoglycan (GAG) chain. DCN exists as a dimer in physiological solutions and is the best characterized member of the growing family of SLRPs. Structurally, it has a domain of tandem leucine-rich repeats (LRRs, altogether 12 LRRs), flanked on both sides by two cysteine-rich regions. Decorin dimer structure (from PDB 1XKU). Images prepared with JMOL program. The $\mathrm{N}$-terminus is in the "middle" of the anti-parallel homodimer. 